\title{
Coming of age? Association for Medical Humanities holds first annual conference
}

\section{A Greaves, H M Evans}

\section{Medical humanities first conference at Durham University}

$l^{n}$ our December 2001 issue we carried a small notice announcing a meeting in the University of Birmingham Medical School, at which a new body, the Association for Medical Humanities in the United Kingdom and Ireland, was to be launched. This was a small but important step in the development of the medical humanities as a field of study in these shores, and it took forward the work of a more exploratory body, the Council for Medical Humanities, which the Nuffield Trust had sponsored over the preceding two or three years.

That meeting, as subsequently reported, attracted around fifty participants from around Britain, representing many disciplines and levels of seniority within clinical health care as well as academic subjects both from the humanities and from those comprising, or related to, medicine. The association was duly launched as envisaged, and its constitution was established with the remit of promoting the medical humanities in education, health care and research. A council was elected, and given the early task of arranging the first of what it was hoped would be an annual series of expressly academic conferences, which would promote and develop consensus regarding solid intellectual foundations for medical humanities as a field of study. That task has now been undertaken.

More than a year in the making, the association's first conference was duly convened in July of this year at Collingwood College in the University of Durham, and we are pleased to devote this editorial to a brief description of the conference, both because of its significance in the development of medical humanities as a field of university study, and because of the affiliation that was there proposed, between the association and this journal. (Many of our readers will be aware that a parallel affiliation, though much older and arising in as it were the opposite direction, exists between our parent journal, the Journal of Medical Ethics, and the Institute of Medical Ethics which launched and now co-owns it.)

Durham as a location was chosen partly because the university there is home to the Centre for Arts and Humanities in Health and Medicine (CAHHM), one of the academic groupings that has been at the forefront in developing medical humanities in Britain; and of course partly because of its delightful physical setting, a reliable "winner" with visitors, including the overseas participants which an academic conference seeks to attract. In the event, some sixty delegates attended of whom several were from abroad, with the United States being the most strongly represented overseas grouping.

The vice chancellor of Durham University, Professor Sir Kenneth Calman, who has for many years been prominent in promoting medical humanities, gave a highly personal and stimulating opening keynote address, setting the tone for a conference which was to prove a friendly and informal as well as an educational experience. The conference was substantially organised around a structure of parallel sessions, so as to enable the presentation of a large number of short papers with time for discussion.

The themes of these sessions were chosen in terms of their forming serious intellectual inquiries-resulting, as the organisers would freely admit, in titles that are somewhat less than journalistic. They generally comprised questions of importance to any attempt to establish medical humanities as both a credible field of university level inquiry, and as a practical resource for the development of professional health care that is humane as well as effective. The questions were: What are the characteristics of humanities in medicine; what are the intended outcomes of humanities components in the medical curriculum, and how can they be measured; what does medicine itself offer to the humanities as a "cultural resource"; what is interdisciplinarity, and how do humanities, social sciences, and natural sciences converse with each other, and what contribution can humanities make to the understanding and management of chronic illnesses? A sixth theme was more simply entitled Lifelong medical education, the arts and humanities.

For the conference delegates it was, to judge by many individual responses, rewarding to attend presentations and participate in discussions that were stimulating and of a generally high standard, admirably befitting the aspirations of an inaugural conference. For the organisers this was both gratifying and a considerable relief. For the presenters themselves it was a testimony, and from the viewpoint of this journal as well as of the association, there was a very substantial satisfaction in seeing the seriousness with which the field of inquiry was being pursued: medical humanities was seen to be "coming of age".

The conference also enjoyed a second keynote address, this time delivered by Professor Howard Brody from Michigan State University, who has been involved with medical humanities in the United States for many years. His presentation, one of the highlights of the conference, focused on a genuinely interdisciplinary study of the work of the celebrated Victorian physician Dr John Snow (fittingly enough for a conference in this location, in that Yorkshire born Snow had trained as a general practitioner in nearby Newcastle, and has one of the university's newest colleges named after him). Besides his ground breaking work on the transmission of infection in a cholera epidemic, Snow was one of the first physicians to experiment with anaesthesia, administering anaesthetic to a grateful Queen Victoria at the birth of two of her children despite considerable and influential opposition from the church.

Professor Brody showed how a reexamination of Snow's work, taking account of his breadth of interest, and examining it from a range of different disciplinary perspectives, revealed a very different and more rounded view of the man and his work than simply the symbolic (and certainly apocryphal) drama concerning the removal of the handle of the Broad Street pump, for which he is currently and misleadingly celebrated. Snow's thought spanned both the technical and the social aspects of medicine in his time and, by recapturing this through convincingly interdisciplinary research, Brody painted a different picture of Snow's world, in the 
process providing a rich resource for a better understanding of the role of medical humanities today. (The multiauthored book arising from the work that Brody described has recently appeared to an enthusiastic reception, and we hope to review the book in a future issue of this journal. ${ }^{1}$ )

Medical humanities is unusual in that, by its nature, it attracts people from a great diversity of both disciplinary and professional backgrounds; since this was the first annual conference, a very important function was for delegates simply to get to know each other. During the two days one heard many snippets of fascinating conversations, but one observation in particular which sticks in the mind came from Cecil Helman, a well known general practitioner and influential medical anthropologist. He observed that he had been doing medical humanities all his professional life, but had only recently become aware of it. It was not so much that he had joined an already existing medical humanities, but that those with a certain perspective on their life and work were-indeed, are-inevitably being drawn together in an emerging field of inquiry and endeavour for which "medical humanities" is the right and proper name.

In this endeavour, the Durham conference was another important step in the advancement of medical humanities, and the delegates were appreciative of the efforts of the association, its council, the steering group charged with overseeing the construction of the conference, and those individuals at CAHHM who, on behalf of the association, bore the brunt of the conference's organisation and administration. All these are to be congratulated for the conference's success, but we should remind ourselves that the most substantial reason for its success inevitably lay with the enthusiasm, intellectual seriousness, active participation, and sheer good will of the delegates as a whole. Indeed, it is the delegates themselves who provide the most solid evidence for the successful maturing of medical humanities as a field of inquiry, and for its having a bright and exciting future. We look ahead now to the association's second annual conference, which will be held at the University of Wales, Swansea in July 2004 and where, this journal hopes and confidently expects, the process will be renewed.

$J$ Med Ethics; Medical Humanities 2003;29:57-58

a.......................

Authors' affiliations

D A Greaves, Centre for Philosophy and Health Care, School of Health Science, University of Wales Swansea, Singleton Park Swansea SA2 8PP, UK

H M Evans, Centre for Arts and Humanities in Health and Medicine, University of Durham, 14/15 Old Elvet, Durham DH1 3HP, UK

Correspondence to: D A Greaves:

d.a.greaves@swansea.ac.uk

\section{REFERENCE}

1 Vinten-Johansen $\mathbf{P}$, Brody $\mathrm{H}$, Paneth $\mathrm{N}$, et al. Cholera, chloroform and the science of medicine: a life of John Snow. New York: Oxford University Press, 2003

\section{Retiring Editor - Dr David Greaves}

This is the last issue for which David Greaves will be a joint editor; David has recently retired from professional academic life and has decided that the time has come to retire also as joint editor of this journal. I would like to pay tribute to David as the person whose forward thinking, on the identification and development of medical humanities as an area of study, led directly to the suggestion that such development would benefit from a serious academic journal in the field. It was natural that he should then be centrally involved in jointly developing a proposal for such a journal and, subsequently, that he became a founding coeditor of the journal when BMJ Specialist Journals endorsed the idea and became our publisher. The area of study as a whole, and this journal in particular, owes a great debt to David's vision and scholarly tenacity. We wish him well. 